\title{
Fluorescence anisotropy microplate assay for analysis of steroid receptor-DNA interactions
}

\author{
Stanley Y. Wang ${ }^{1}$, Bonnie S. Ahn ${ }^{1}$, Rebecca Harris ${ }^{1}$, Steven K. Nordeen², and David J. Shapiro ${ }^{1}$
}

BioTechniques 37:807-817 (November 2004)

\begin{abstract}
To analyze the interactions of steroid/nuclear hormone receptors with their DNA response elements, we used ultra low-volume microplates to develop a simple and rapid fluorescence anisotropy assay. The novel fluorescence anisotropy microplate assay (FAMA) was applied to the binding of estrogen and progesterone receptors (ER and PR, respectively) to their respective DNA response elements. The FAMA offers exceptional flexibility in its ability to test a variety of binding conditions and DNA response elements in real time. This assay can differentiate between, and quantitate, sequence-specific and nonspecific binding of receptors to DNA and offers the possibility of true solution analysis of the interaction of coregulators with the estrogen response element (ERE)-ER complex. To test suitability for screening large compound libraries, we demonstrated that the FAMA generates stable signals for more than 4 hours, is insensitive to inhibition by dimethyl sulfoxide (DMSO), and works well in 384-well plates. We analyzed inhibition of receptor-DNA interaction by several zinc chelators and demonstrated zinc dependence and a generally higher sensitivity to inhibition for PR-progesterone response element (PRE) interactions than for ER-ERE interactions. The FAMA is the first system suitable for screening large compound libraries to identify novel compounds that antagonize (or stimulate) binding of steroid receptors to their DNA response elements.
\end{abstract}

\section{INTRODUCTION}

The steroid receptors including estrogen, progesterone (ER and PR, respectively), and androgen receptors comprise a subfamily of the larger nuclear receptor superfamily of transcription regulators. The receptors contain discrete functional domains for hormone binding, transactivation, and DNA binding [DNA binding domain (DBD)]. The DBD contains two structurally and functionally essential $\mathrm{Cys}_{4}$ zinc-finger motifs.

The critical role of the steroid receptors, along with their activating hormones, in normal development and in pathologies such as osteoporosis and breast, uterine, and prostate cancer has led to the development of receptorbased therapies $(1,2)$. These therapies depend on agents such as raloxifene and tamoxifen that exert their activities by binding in the hormone binding pockets of the steroid receptors. Very recently, proof-of-principle was provided for a new class of potential breast cancer therapeutic agents that disrupt the binding of ER to estrogen response elements (EREs) by modifying the zinc fingers of the ER DBD (3). Further interest in the binding of steroid receptors to their DNA target sites has been stimulated by recent work emphasizing the role of naturally occurring imperfect EREs and progesterone/glucocorticoid response elements (PREs/GREs) in modulating the activity of steroid receptors (4-14). Therefore, there is strong interest in developing new ways to both analyze the interaction of steroid receptors with their response elements and to screen large libraries for compounds that target receptor-DNA interactions.

The electrophoretic mobility shift assay (EMSA) is the most widely used technique for the analysis of steroid/ nuclear receptor:hormone response element (HRE) interactions. However, EMSA is slow and laborious, is not a true equilibrium method, uses radioisotopes, and does not provide realtime data. In pioneering work, Boyer et al. (15) and Ozers et al. (16) described the application of fluorescence anisotropy to ER:ERE interactions. In this assay, when polarized light is used to excite a free fluorophor-labeled oligonucleotide, the rapid rotational diffusion of the oligonucleotide results in depolarized emitted light. However, protein binding greatly reduces the mobility of the oligonucleotide, resulting in more polarized emitted light. Thus, protein:DNA interaction is observed as a change in fluorescence anisotropy. Although fluorescence anisotropy and fluorescence polarization are both expressions of the same phenomenon, we used fluorescence anisotrophy in our studies because the values are easier to manipulate. The fluorescence anisotropy assay is performed in solution and provides true equilibrium analysis, real-time kinetic data, and a reduced sensitivity to artifacts of quenching and exogenous fluorescence.

However, the previously described assay $(15,16)$ has not stimulated wide-

\footnotetext{
${ }^{1}$ University of Illinois, Urbana, IL, and ${ }^{2}$ University of Colorado Health Sciences Center, Denver, CO, USA
} 
Table 1. Sequences of the Oligonucleotide Probes Used in FAMA and EMSA

\begin{tabular}{|ll|}
\hline Probe Name & Probe Sequence \\
\hline cERE (30 nt) & 5'-F-CTAGATTACAGGTCACAGTGACCTTACTCA-3' \\
PS2 & 5'-F-CTAGATTACAGGTCACGGTGGCCACACTCA-3' \\
ERU & 5'-F-AGATTACACTGGGGGGACCCTGACCTGACCCTGCTCCCAGCTCTGACCTTACTCAG-3' \\
cPRE/GRE & 5'-F-CTAGATTACAGAACAATCTGTTCTTACTCA-3' \\
RANDOM & 5'-F-CTAGACTTACGCTGATGACTTCGGTACGCA-3' \\
cERE (39 nt) & 5'-AGCTTCTCTATTAGGTCACTGTGACCTTCATCTGAAGCT-3' \\
F, Fluorescein; nt, nucleotides; FAMA, fluorescence anisotropy microplate assay; EMSA, electrophoretic mobility shift assay; cERE, consensus ERE; ERE, \\
estrogen response element; PRE, progesterone response element; GRE, glucocorticoid response element; ERU, estrogen responsive unit.
\end{tabular}

spread use because it only assays samples one at a time and uses large sample volumes, necessitating the use of very large quantities of receptor. We describe a simple and rapid method for the fluorescence anisotropy-based analysis of steroid receptor:DNA interactions in ultra low-volume 96-well microplates and in 384-well microplates. The fluorescence anisotropy microplate assay (FAMA) we developed should find wide application because it features small reaction volumes and a multiwell microplate platform that provides for maximal use of scarce receptor protein and facile comparison of different binding conditions. The FAMA can also be used to study the interaction of the ERERE complex with receptor-associated proteins.

Although fluorescence anisotropy has been widely used for over 70 years, it was the development of sensitive instruments capable of fluorescence anisotropy measurements from samples in microplates in the late 1990s that stimulated the application of fluorescence anisotropy to high-throughput screening (HTS; References 17-20). To develop the FAMA for HTS, we adapted the FAMA to 384-well microplates and demonstrated well-to-well reproducibility, insensitivity to inhibition by dimethyl sulfoxide (DMSO), ethanol and methanol, and stability of the anisotropy signal for more than 4 hours. The FAMA represents the first system suitable for HTS of large compound libraries to identify a new class of therapeutic agents that act by modulating steroid receptor:DNA interactions $(1,2)$. To validate the use of FAMA in screening, we began with a known inhibitor, the zinc chelator, 1,10phenanthroline (21). We then screened several less studied zinc chelators to evaluate their abilities to inhibit binding of $E R \alpha, E R \beta$, and human progesterone receptor-B (hPR-B) to their respective response elements. We found that PR: PRE interactions were more sensitive to inhibition than ER:ERE interactions.

\section{MATERIALS AND METHODS}

\section{Proteins}

Full-length FLAG ${ }^{\circledR}$-epitope-tagged human ER $\alpha$ (fhER $\alpha)$ or fhER $\beta$ was expressed, in the presence of $200 \mathrm{nM}$ $17 \beta$-estradiol $\left(\mathrm{E}_{2}\right)$, and purified, in the presence of $20 \mathrm{nM} \mathrm{E} \mathrm{E}_{2}$, essentially as we previously described $(22,23)$. The purity of the fhER $\alpha$ was greater than 90\% using the Silver Stain Plus kit (Bio-Rad Laboratories, Hercules, CA, USA). ER concentration was determined by Western blot analysis with an $\alpha$-FLAG M2Ab (Sigma, St. Louis, MO, USA) and comparison with a standard curve of unliganded, purified fhER $\alpha$, whose concentration was previously determined by a ${ }^{3} \mathrm{H}-\mathrm{E}_{2}$ (tritiated estradiol) binding assay. Full-length R5020-liganded human progesterone receptor hPR-B was purified as previously described (24). ER $\alpha$ antibodies ER-Ab1 and ER-Ab10 were from Lab Vision (Fremont, CA, USA).

\section{Compounds}

TPEN [N,N, $\mathrm{N}^{\prime}, \mathrm{N}^{\prime}$-Tetrakis (2pyridylmethyl) ethylenediamine], 1,10-phenanthroline, BPS (bathophenanthroline disulfonic acid), and PDTC (pyrrolidine dithiocarbamate) were from Sigma. The compounds were dissolved in water (BPS, PDTC), methanol (1,10-phenanthroline), or ethanol (TPEN).

\section{Oligonucleotides}

Sense strand oligonucleotides (Table 1) were synthesized with fluorescein (6-FAM) at their $5^{\prime}$ ends using phosphoramidite chemistry and PolyPak ${ }^{\mathrm{TM}}$ II (Glen Research, Sterling, VA, USA)purified by the Biotechnology Center (University of Illinois, Urbana, IL, USA). Oligonucleotide concentrations were calculated from $\mathrm{A}_{260}$ and the degree of fluorescence incorporation (FI) was calculated by the method of Ozers et al. (16). The FI ratios for all labeled oligonucleotides were approximately $60 \%$. The labeled sense strands were annealed with equimolar amounts of unlabeled antisense strands. Unlabeled competitor oligonucleotides cPRE/GRE, RANDOM, and a 39nucleotide long concensus ERE (cERE; see Table 1) oligonucleotide were also annealed. The ERE sequences in the oligonucleotides used for EMSA were the same as the DNA sequences of the fluorescence probes (A. Krieg, 2003. $\mathrm{Ph}$.D. thesis, University of Ilinois).

\section{Electrophoretic Mobility Shift Assays}

EMSA was carried out as we recently described (22). Free probe and protein-DNA complexes were quantitated using a Storm ${ }^{\circledR} 840 \mathrm{Gel}$ and Blot Imaging System and ImageQuant ${ }^{\mathrm{TM}}$ 5.0 (both from Molecular Dynamics, Sunnyvale, CA, USA). The percent of DNA bound was calculated as: [(protein:DNA counts)/((protein:DNA counts) + (free probe counts)) $]^{*} 100$.

\section{Fluorescence Anisotropy Assays}

Fluorescein-labeled oligonucleotides for ER assays were diluted to 
$1 \mathrm{nM}$ in either a low salt anisotropy buffer (LSAB) containing the nonspecific competitor poly-dI:dC $(15 \mathrm{mM}$ Tris-HCl, pH 7.9, $65 \mathrm{mM} \mathrm{KCl,} 1 \mathrm{mM}$ dithiothreitol (DTT), 5\% glycerol, $0.05 \%$ Nonidet $^{\mathrm{TM}} \mathrm{P}-40$ (NP-40), 100 ng poly dI:dC), or in a high salt anisotropy buffer (HSAB, $15 \mathrm{mM}$ Tris-HCl, pH 7.9, $150 \mathrm{mM}$ $\mathrm{KCl}, 1 \mathrm{mM}$ DTT, 5\% glycerol, $0.05 \%$ NP-40) without poly dI:dC. Some assays also contained $15 \mu \mathrm{g}$ bovine serum albumin (BSA; Promega, Madison, WI, USA). The fluorescein-labeled oligonucleotide for PR assays was diluted to $1 \mathrm{nM}$ in an anisotropy buffer containing $10 \mathrm{mM}$ Tris- $\mathrm{HCl}$, pH 7.9, $150 \mathrm{mM} \mathrm{NaCl}, 5 \mathrm{mM}$ DTT, 5\% glycerol, 1 mM EDTA, 2 $\mathrm{mM} \mathrm{MgCl}, 1 \mu \mathrm{g}$ ovalbumin, and $100 \mathrm{ng}$ poly-dA:dT. The fhER and crude fhER-containing baculovirus extracts were diluted to appropriate starting concentrations with BC300 buffer (25). The hPR was diluted to appropriate starting concentrations with receptor dilution buffer (12.7 $\mathrm{mM}$ Tris-HCl, $\mathrm{pH} 7.9,63.5$ $\mathrm{mM} \mathrm{NaCl}, 6.35 \%$ glycerol, $6.34 \mathrm{mM}$ DTT, $1.27 \mathrm{mM}$ EDTA, $2.54 \mathrm{mM} \mathrm{MgCl}_{2}$, $0.05 \mu \mathrm{g} / \mu \mathrm{L}$ ovalbumin). Buffers containing the fluorescein-labeled oligonucleotides were first added to the wells of a black 96-well, low-volume, high-efficiency $\mathrm{HE}^{\mathrm{TM}}$ microplate (Molecular Devices) (Figures 1-4) or a black 384-well round-bottom microplate (Greiner BioOne, Longwood, FL, USA) (Figure 5). The indicated amounts of hER or hPR were added to the wells in a final reaction volume of $20 \mu \mathrm{L}$, and the reactions were mixed by pipetting. Reactions were incubated at room temperature in the dark. Anisotropy values, automatically calculated by the Xfluor4 software, were measured using the fluorescence polarization function of the Ultra Evolution Multifunctional Microplate Reader (Tecan, Research Triangle Park, NC, USA). Successful assays were also performed on the Analyst ${ }^{\circledR}$ AD Assay Development System (Molecular Devices). For binding affinity analysis, a percent bound value was calculated at each receptor concentration using the following equation: (anisotropy change/ max anisotropy change) $* 100$. After plotting percent probe bound versus receptor concentration, an approximate $\mathrm{K}_{\mathrm{d}}$ (dissociation constant) was deter-
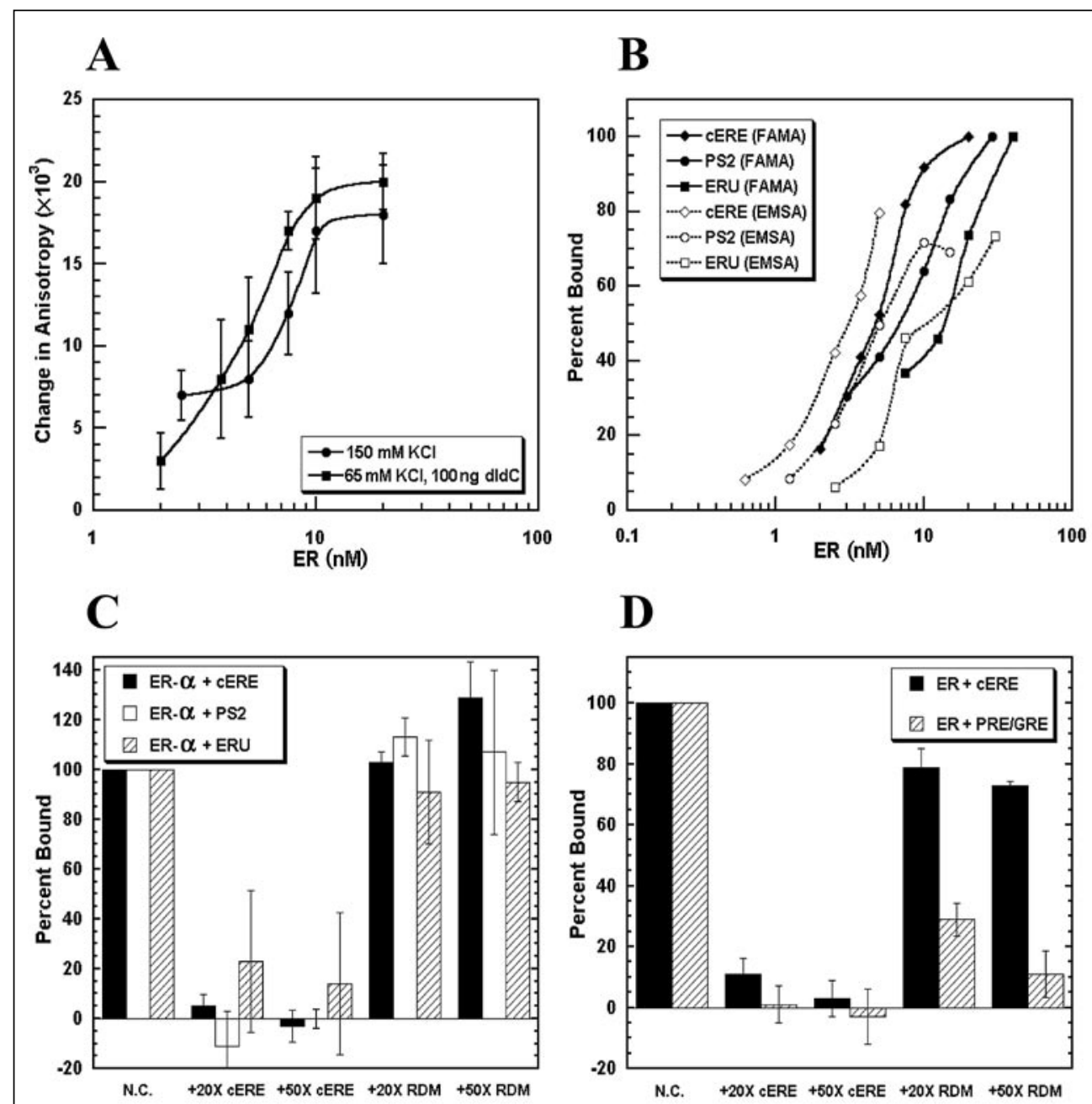

Figure 1. Specificity and flexibility of the FAMA for analysis of hER $\alpha$-ERE interactions in small reaction volumes. (A) Binding of $h E R \alpha$ to the consensus ERE (cERE) using FAMA. Increasing amounts of $h E R \alpha$ were incubated with $1 \mathrm{nM}$ fluorescein-labeled cERE in the low salt anisotropy buffer (LSAB) or the high salt anisotropy buffer (HSAB) + bovine serum albumin (BSA). "Change in anisotropy" represents the difference between anisotropy values measured at each concentration of hER $\alpha$ and the anisotropy measured with no added hER $\alpha$. The data in panels A, C, and D represent the average $\pm \mathrm{SD}$ for at least three independent experiments. (B) Comparison of FAMA and EMSA for the analysis of binding of hER $\alpha$ to imperfect, naturally occurring EREs. Samples containing $1 \mathrm{nM}$ of fluorescein-labeled ERE and increasing amounts of $\mathrm{hER} \alpha$ were incubated in LSAB + BSA. EMSA was carried out as described in Materials and Methods. Percent bound is plotted on the y-axis and was calculated as described in Materials and Methods. Competition experiments to (C) assess specificity of hER $\alpha$ :DNA binding (LSAB) and (D) differentiate between specific and non-sequence-specific binding (LSAB without poly dI:dC.) Incubations contained $1 \mathrm{nM}$ fluorescein-labeled cERE or PRE/GRE and the indicated molar excess of unlabeled cERE or nonspecific RANDOM (RDM) oligonucleotide. N.C. $=$ no competitor. Percent bound values on the $y$-axis were calculated by dividing the measured anisotropy by the anisotropy measured in samples without any added competitor. Actual values for background and maximum anisotropy in each panel were: (A) 65 and 85 for LSAB and 43 and 61 for HSAB; (B) 65 and 85 for cERE, 72 and 98 for PS2, and 58 and 76 for ERU. For samples with no competitor: (C) 35 and 59 for cERE, 36 and 51 for PS2, and 43 and 50 for ERU; (D) 23 and 66 for cERE and 28 and 67 for PRE/GRE. FAMA, fluorescence anisotropy microplate assay; ER, estrogen receptor; PR, progesterone receptor; ERE, estrogen response element; EMSA, electrophoretic mobility shift assay; PRE, progesterone response element; GRE, glucocorticoid response element; ERU, estrogen responsive unit. 
mined as the receptor concentration at which $50 \%$ of the probe was bound.

Competition experiments and antibody binding used amounts of fhER $\alpha$ or hPR-B required to achieve $70 \%-$ $80 \%$ binding of probe in the LSAB or the PR anisotropy buffer. The indicated amounts of unlabeled competitor oligonucleotides or anti-ER $\alpha$ antibody or normal mouse immunoglobulin $\mathrm{G}$ (IgG) were added.

Screening experiments used amounts of fhER $\alpha$, fhER $\beta$, and hPR-B required to achieve $70 \%-80 \%$ binding of probe in the ER LSAB or the PR anisotropy buffer. The receptor proteins were incubated with either the solvent or compounds for $30 \mathrm{~min}$ at room temperature before the addition of the fluorescein-labeled oligonucleotides. The 1,10-phenanthroline-mediated inhibition of ER $\alpha$ :cERE binding was blocked by pre-incubating 1,10-phenanthroline with the indicated amount of $\mathrm{ZnCl}_{2}$ at $4^{\circ} \mathrm{C}$ for $10 \mathrm{~min}$ before exposure to ERo.

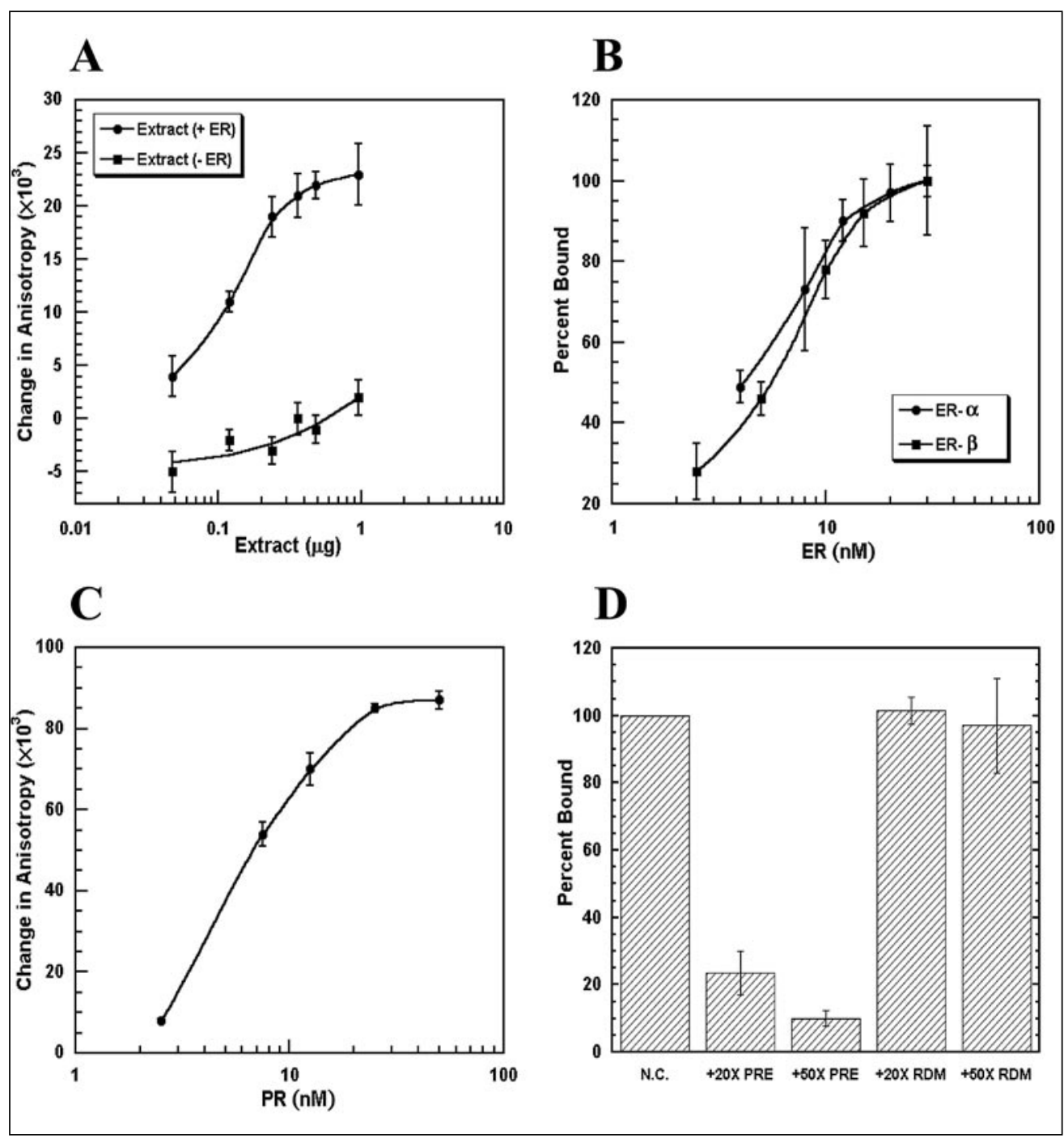

Figure 2. FAMA analysis of binding of crude extracts containing $h E R \alpha$ and purified $h E R \beta$ and hPR-B to their HREs. (A) Increasing amounts of crude $h E R \alpha$-containing extracts from baculovirus-infected insect cells or control ER-negative insect cells or (B) increasing amounts of purified hER $\alpha$ and hER $\beta$ were each incubated with $1 \mathrm{nM}$ fluorescein-labeled consensus ERE (cERE) in the low salt anisotropy buffer (LSAB). (C) Increasing amounts of purified hPR-B were incubated with $1 \mathrm{nM}$ fluorescein-labeled cPRE/GRE in the PR anisotropy buffer. "Change in anisotropy" is described in the Figure 1 legend. (D) Competition experiments to assess the specificity of hPR-B-cPRE/GRE binding. The indicated fold molar excess of unlabeled cPRE/GRE (PRE) or nonspecific RANDOM (RDM) oligonucleotide was used with $1 \mathrm{nM}$ fluorescein-labeled cPRE/GRE. N.C. $=$ No Competitor. The anisotropy change for hPR-B bound to the cPRE/GRE was set equal to $100 \%$. All of the data (A-D) represent the average of at least three independent experiments \pm SD. Actual values for background and maximum anisotropy each panel were: (A) 33 and 55 for extract (+ER) and 33 and 34 (-ER); (B) 39 and 68 for ER $\alpha$ and 29 and 71 for ER $\beta$; (C) 51 and 138 for hPR-B; (D) 47 and 114 for hPR-B no competitor. FAMA, fluorescence anisotropy microplate assay; hPR-B, human progesterone receptor-B; ER, estrogen receptor; ERE, estrogen response element; PR, progesterone receptor; PRE, progesterone response element; GRE, glucocorticoid response element; HREs, hormone response elements.

\section{RESULTS}

In preliminary studies, we identified conditions for a fluorescence anisotropy assay of steroid receptor binding to HREs amenable to low reaction volumes and a microplate format. To test the FAMA, we analyzed binding of increasing amounts of $\mathrm{hER} \alpha$ to the cERE in a 20$\mu \mathrm{L}$ reaction in an ultra lowvolume 96-well microplate using the high salt buffer. We initially chose $150 \mathrm{mM} \mathrm{KCl}$ because it is physiologically relevant and because previous reports and our initial studies suggest that this is the minimum salt concentration needed for sequence-specific binding of $h E R \alpha$ to the cERE without the addition of nonspecific competitor DNA. A robust hER $\alpha$ :cERE binding curve with a $\mathrm{K}_{\mathrm{d}}$ of approximately $5.4 \mathrm{nM}$ was obtained (Figure 1A). To demonstrate the flexibility of the assay and to analyze binding under conditions similar to those previously used in EMSA, we also analyzed binding of hER $\alpha$ to the cERE in the low salt buffer that contains poly $\mathrm{dI}: \mathrm{dC}$ as nonspecific competitor (to reduce non-sequencespecific binding of ER $\alpha$ to the fluorescent cERE probe) and BSA (Figure 1A). The $\mathrm{K}_{\mathrm{d}}$ of approximately $4.7 \mathrm{nM}$ was similar to that observed with the HSAB (Figure 1A). Although the added BSA increased the fluorescent ERE background, it did not affect the anisotropy change or the $\mathrm{K}_{\mathrm{d}}$ value. 


\section{RESEARCH REPORT}

To test the utility of FAMA with lower affinity, naturally occurring, imperfect EREs and to compare data obtained with the FAMA to data obtained using EMSA, we analyzed binding to the cERE, the widely studied imperfect ERE in the $p S 2$ gene and the quite different estrogen responsive unit (ERU) in the proteinase inhibitor-9 gene (Table 1; References 25 and 26). Using FAMA, relative $K_{d}$ values were approximately $4.7,7.2$, and $12.6 \mathrm{nM}$ for cERE, $\mathrm{pS} 2$, and ERU sequences, respectively, while relative $K_{d}$ values using EMSA were approximately 3.2, 6.3, and $12 \mathrm{nM}$ (Figure 1B). To test for specificity in the binding of $h E R \alpha$ to the different EREs in our FAMA assay, we performed competition experiments. A 20-fold molar excess of unlabeled cERE was able to effectively compete with all 3 of the fluorescent ERE probes for binding to $h E R \alpha$, while even a 50-fold excess of random oligonucleotide did not compete for binding (Figure 1C). The overall anisotropy change for the lower affinity hER $\alpha$ ERU binding is more than 3-fold lower (see Figure 1C legend); therefore, the anisotropy change is more sensitive to signal variation and more prone to large measurement errors.

We used competition experiments to test the ability of the FAMA to distinguish between nonspecific and sequence-specific binding to DNA. The affinity of steroid receptors for nonspecific DNA is too low for nonspecific interactions to be studied using standard EMSA. Differentiating between these modes of interaction is potentially important in determining how steroid receptors locate and bind to HREs in the presence of a large excess of nonspecific chromosomal DNA. In initial studies, we found that using the low salt buffer without poly dI:dC, hER $\alpha$ bound efficiently to the cPRE/GRE (which differs by two nucleotides per half site from the cERE) as well as to the cERE (data not shown). Because previous studies have shown that hER $\alpha$ exhibits negligible binding and transactivation with the cPRE/GRE in vivo, this interaction probably represents non-sequencespecific binding of hER $\alpha$ to the cPRE/ GRE. To test this hypothesis, we bound $\mathrm{hER} \alpha$ to the labeled cERE and to the 
cPRE/GRE in the LSAB without added poly $\mathrm{dI}: \mathrm{dC}$ and in the presence of a 20or 50-fold molar excess of unlabeled cERE or the nonspecific RANDOM oligonucleotide. Both the unlabeled cERE and RANDOM oligonucleotide effectively competed off hER $\alpha$ binding to the cPRE/GRE (Figure 1D), but only the unlabeled cERE was effective at competing off $h E R \alpha$ binding to the fluorescent cERE probe. Because these experiments were done in the low salt buffer without poly dI:dC, hER $\alpha$ binding to the cERE includes a low level of non-sequence-specific binding and a much higher level of sequence-specific binding to the cERE. The slight decline in anisotropy we observe in the low salt buffer without poly $\mathrm{dI}: \mathrm{dC}$ is due to this nonspecific binding being competed away by the RANDOM oligonucleotide. In contrast, in the low salt buffer with poly $\mathrm{dI}: \mathrm{dC}$, the proportion of $\mathrm{hER} \alpha$ nonspecifically bound to the ERE, is negligible, and the RANDOM oligonucleotide does not reduce binding of $h E R \alpha$ to the cERE (compare
Figure 1C with Figure 1D).

Because it has been suggested that accessory proteins present in cell extracts modify binding of ER $\alpha$ to the cERE, it may occasionally be advantageous to employ cell extracts (23). Cell extracts also eliminate the need to purify the receptor. Consequently, we tested the ability of the FAMA to measure $\mathrm{hER} \alpha$ binding to the cERE in crude cell extracts. A low nonsaturable level of binding to the cERE was observed for the control cell extract from uninfected insect cells, while the expected saturable binding curve was obtained for the extract containing $\mathrm{hER} \alpha$ from baculovirus-infected insect cells (Figure 2A).

While these studies demonstrated the utility of FAMA for analyzing binding of $\mathrm{hER} \alpha$ to EREs, we wanted to determine whether the assay was suitable for more general use with steroid receptors. ER also exists as a second isoform, the approximately $55 \mathrm{kDa}$ $\mathrm{hER} \beta$, with a different tissue distribution, and likely, different functions than the approximately 66 $\mathrm{kDahER} \alpha$ (27). Previous studies suggested that hER $\beta$ exhibits lower affinity binding to the cERE than hER $\alpha$ (28). We tested binding of increasing amounts of hER $\beta$ to the cERE. Using FAMA, a saturable binding curve was obtained with a $\mathrm{K}_{\mathrm{d}}$ of approximately $5.8 \mathrm{nM}$ (Figure 2B), an affinity for the cERE only slightly lower than is exhibited by hER $\alpha$.

To test the versatility of FAMA, we analyzed binding of a different steroid receptor, hPR-B, to its recognition sequence, the cPRE/GRE. We generated a highquality saturated binding curve with an approximate $K_{d}$ of $7.4 \mathrm{nM}$ (Figure 2C). Because a 50fold molar excess of receptor. 
cPRE/GRE effectively competed away binding to the fluorescent cPRE/GRE probe and a 50-fold excess of the RANDOM oligonucleotide did not compete, binding of hPR-B to the cPRE/GRE was sequence-specific (Figure 2D). These studies demonstrate that the FAMA has broad utility for analyzing interaction of steroid receptors with their HREs. The change in anisotropy observed for hPR-B:cPRE/GRE binding is approximately 3 -fold greater than we observed with hER $\alpha$ :cERE binding (compare Figure 1A and Figure $2 \mathrm{C}$ ). Because hPR-B has a much higher molecular weight than ER (approximately 120 $\mathrm{kDa}$ for PR vs. approximately $66 \mathrm{kDa}$ for hER $\alpha$ ), the larger protein-DNA complex formed should result in slower rotational diffusion of the complex, and consequently, a larger change in anisotropy.

The enhanced anisotropy change with the larger PREhPR-B complex suggests using the FAMA assay to look at interactions of the ER:ERE complex with the p160 family of steroid receptor coactivators (29). Previous ER $\alpha-p 160$ coactivator interaction studies employed fluorescent coactivator fragments or peptides, without including ERE interactions $(30,31)$. To begin to address the possibility of looking directly at interactions of the ERE-ER $\alpha$ complex with unlabeled coactivators, we analyzed interactions of the $\mathrm{hER} \alpha$ : cERE complex with anti-ER antibodies whose molecular weight of approximately 150 $\mathrm{kDa}$ is similar to those of the p160 coactivators. The addition of increasing amounts of the antibodies ER Ab-10 and ER Ab- 1 to a saturated ER $\alpha$ cERE complex increased the anisotropy change by up to 1.8- and 1.6-fold, respectively. Equivalent amounts of a control IgG had no effect on the anisotropy change (Figure 3).

Screening compound libraries to identify potential breast cancer therapeutic agents that work by disrupting binding of ER to EREs represents an important potential application of the FAMA. HTS is facilitated by assays that show high well-to-well reproducibility, stability of the assay signal over time, and insensitivity to DMSO and other solvents. The FAMA demonstrated minimal variation in anisotropy across multiple wells, the assay was stable for more than 4 hours with ER $\alpha, E R \beta$, and PR bound to their response elements, and DMSO, ethanol, or methanol (at $5 \%-15 \%$ by volume) did not inhibit the assay (data not shown).

As proof-of-principle for use of the FAMA to identify inhibitors of ER-ERE binding, we tested a known inhibitor (21), the zinc chelator 1,10-phenanthroline. We observed a concentrationdependent inhibition of $E R \alpha$ binding to the cERE, with maximum inhibition of approximately $80 \%$ at $1000 \mu \mathrm{M}$ 1,10-phenanthroline. Consistent with 1,10-phenanthroline's proposed function as a zinc chelator, inhibition was
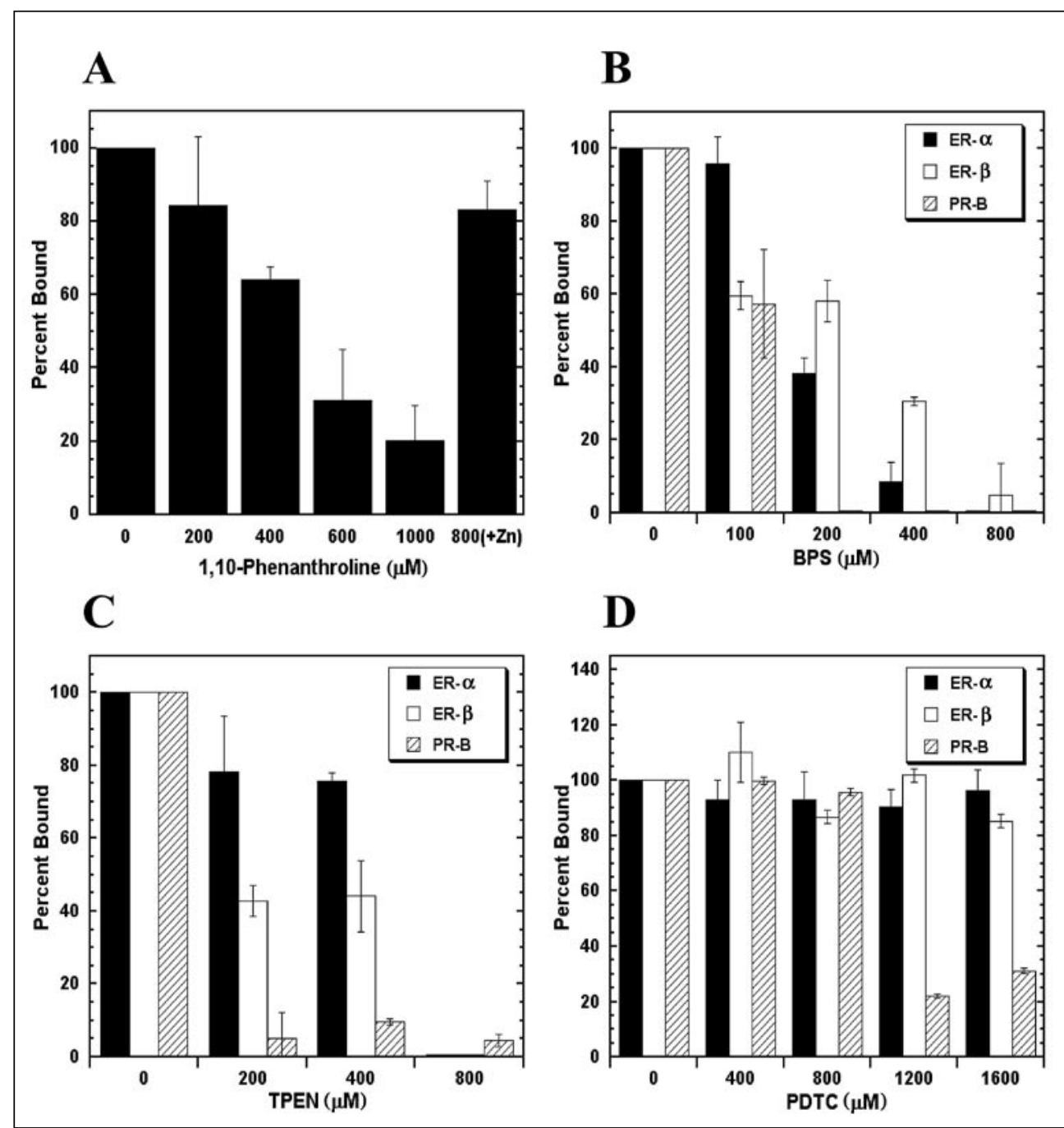

Figure 4. Use of the FAMA to identify inhibitors of steroid receptor-DNA binding. The control samples with no added inhibitor were set equal to $100 \%$. We used receptor concentrations that produce approximately $80 \%$ of maximal binding. The data represent the average of at least three independent experiments \pm SD. (A) Increasing concentrations of 1,10-phenanthroline were added to the $\mathrm{hER} \alpha$-cERE complex. For the reaction with zinc, $50 \mu \mathrm{M}$ of $\mathrm{ZnCl}_{2}$ was pre-incubated with $800 \mu \mathrm{M}$ 1,10-phenanthroline. (B-D) Increasing concentrations of the indicated zinc chelator were added to the receptor-DNA complex. Actual values for background and maximum anisotropy in samples with no inhibitor were as follows. (A) ER $\alpha: 38$ and 54 (B) ER $\alpha: 28$ and 56; ER $\beta$ : 28 and 69; PR-B: 53 and 110 (C) ER $\alpha: 28$ and 56; ER $\beta$ : 28 and 53; PR-B: 53 and 110 (D) ER $\alpha: 28$ and 56; ER $\beta: 34$ and 58; PR-B: 41 and 111. FAMA, fluorescence anisotropy microplate assay; cERE, consensus ERE; ERE, estrogen response element; TPEN, N,N, $N^{\prime}, N^{\prime}$-Tetrakis (2pyridylmethyl)ethylenediamine; BPS, bathophenanthroline disulfonic acid; PDTC, pyrrolidine dithiocarbamate. 


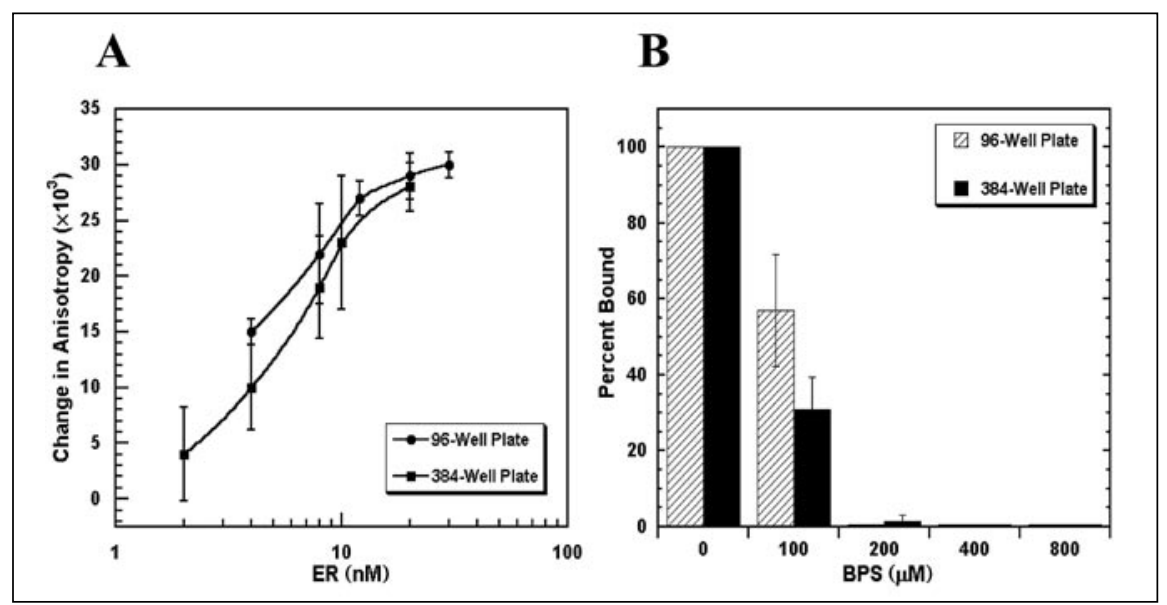

Figure 5. Compatibility of FAMA with the 384-well microplate format. (A) Increasing amounts of $\mathrm{hER} \alpha$ were incubated with $1 \mathrm{nM}$ fluorescein-labeled consensus ERE (cERE) in the low salt anisotropy buffer (LSAB), using 96-well and 384-well microplates. "Change in anisotropy" is as described in the Figure 1 legend. (B) FAMA assay of BPS inhibition of hPR-B binding to the PRE. Assays were carried out as described in Figure 4, using both the 96-well and 384-well microplates. The data represent the average of at least three independent experiments \pm SD. Actual values for background and maximum anisotropy for ER $\alpha$ were as follows. (A) 96-well plate: 38 and 69; 384 well plate: 58 and 86 and for PR (B) No inhibitor; 96-well plate: 53 and 110; 384-well plate: 52 and 129. FAMA, fluorescence anisotropy microplate assay; ERE, estrogen response element; hPR-B, human progesterone receptor-B; ER, estrogen receptor; PRE, progesterone response element; PR, progesterone receptor.

relieved by added zinc (Figure $4 \mathrm{~A}$ ). To determine if the FAMA could be used to identify novel inhibitors that might display selectivity for a specific receptor, we tested several zinc chelators not previously reported to disrupt steroid receptor binding to DNA response elements. PDTC did not inhibit binding of $\mathrm{ER} \alpha$ or ER $\beta$ to the cERE at $400-1600$ $\mu \mathrm{M}$. The data for ER $\alpha$ and ER $\beta$ clustered closely around $100 \%$ binding, demonstrating the reproducibility of the FAMA. PDTC only inhibited PR binding to the PRE at 1200 and 1600 $\mu \mathrm{M}$ (Figure 4D). BPS and TPEN were more potent inhibitors, with BPS showing partial inhibition of binding of PR and ER $\beta$ to their DNAs at $100 \mu \mathrm{M}$ and complete inhibition of binding of all three receptors to DNA by $800 \mu \mathrm{M}$ of BPS and TPEN (Figure 4, B and C). In general, the PR-PRE interaction was most sensitive to inhibition, followed by the ER $\beta$-cERE interaction, with the ER $\alpha$-cERE interaction being the least sensitive to inhibition.

The studies described in Figure 1-4 were carried out in low-volume 96-well plates. Although the $20-\mu \mathrm{L}$ sample volumes are similar to sample volumes normally used in the 384-well plates widely used in HTS, it was important to directly test the sensitivity of the FAMA in the 384-well format. We therefore determined that our assay had the requisite sensitivity for use with ER and PR in the 384-well format. An hER $\alpha$-cERE binding curve generated using a 384well microplate had a $\mathrm{K}_{\mathrm{d}}$ of approximately $4.5 \mathrm{nM}$, which was similar to the binding curve obtained using a 96-well plate (Figure 5A). To test the use of the 384-well microplate with inhibitors of DNA binding, we compared the binding of PR to the PRE in the presence of BPS in the 96- and 384-well microplates. We observed strong inhibition of binding in samples assayed in the 384-well microplates and in the 96-well microplates (Figure 5B). Because the anisotropy changes we observed using the 384-well plates were at least as large those observed using the 96-well plates (Figure 5), the FAMA works well in screening using 384-well plates.

\section{DISCUSSION}

Our initial studies explored the flexibility and specificity of the FAMA. We observed ER $\alpha$-cERE binding using 
different conditions, with $\mathrm{K}_{\mathrm{d}}$ values similar to those previously reported using EMSA. We also directly compared FAMA and EMSA in our testing of lower affinity, naturally occurring, imperfect EREs. Exhaustive DNA binding studies of imperfect EREs by EMSA or other techniques normally require either large amounts of ER or extensive, labor-intensive studies. With its low-volume reactions and multisample capability, the FAMA should prove ideal for the study of these EREs. Further, in contrast to EMSA, the FAMA is a true equilibrium method.

In living cells, steroid receptors must discriminate between bulk DNA and sequence-specific response elements. Because EMSA cannot easily measure the very weak low affinity interactions of steroid receptors with nonspecific DNA, this process has been difficult to study biochemically. In contrast, we show that in the low salt buffer without added poly dI:dC, the FAMA readily assesses nonspecific binding and should greatly facilitate research in this poorly understood area.

One demonstration of the FAMA's versatility is the ability to generate high-quality saturated binding curves with crude whole cell extracts containing hER $\alpha$. Higher concentrations of control ER-negative cell extracts did produce a slight increase in anisotropy, presumably because of nonspecific binding to the cERE. For whole cell extracts that contain very low concentrations of receptor, optimization to reduce nonspecific binding in extracts from a particular source or preparation of nuclear extracts may be useful.

Another demonstration of the FAMA's versatility is the ability to generate high-quality saturated binding curves with steroid receptors whose sizes range from approximately $55 \mathrm{kDa}$ for ER $\beta$ to approximately $120 \mathrm{kDa}$ for PR-B. These studies represent the first fluorescence anisotropy analysis of binding of PR to a PRE. ER is generally considered to have higher affinity for the cERE than most other steroid receptors exhibit for their response elements. Because we effectively measured both PR-PRE interactions and binding of ER to lower affinity imperfect EREs, the FAMA should prove very useful in analyzing the lower affinity interac- tions of other steroid receptors with their response elements.

Our demonstration that binding of monoclonal antibodies to ER results in an approximate 50\% increase in anisotropy compared to the ER-cERE complex strongly suggests that the FAMA can be used to analyze EREER-coregulator interactions. The approximate 8 -fold increase in size from the approximate $18 \mathrm{kDa}$ fluorescent ERE alone to the approximate $150 \mathrm{kDa}$ ERE-ER $\alpha$ complex produces a much larger change in anisotropy than the additional 3-fold change from approximately $150 \mathrm{kDa}$ to the approximate $460 \mathrm{kDa}$ ERE-ER $\alpha$-Ab complex (assuming one molecule of monoclonal antibody is bound to each ER monomer in the ERE-ER dimer complex.)

Currently available small molecule therapeutics that modify steroid receptor action work by binding in the receptor's ligand binding pocket. The need for a new class of therapeutics was emphasized in a recent study of the development of anti-androgen resistant prostate cancers. These researchers concluded that development of new classes of small molecule antagonists that act outside of the receptor's ligand binding pocket would provide a new way to slow the development of tumor resistance (32). Although agents that work by blocking binding of receptors to their response elements represent an obvious class of potential therapeutics, the absence of a suitable system for HTS has complicated the identification of these compounds. We began the process of developing the FAMA for HTS. We find that the FAMA assay is reproducible, stable, insensitive to inhibition by DMSO, and is well suited to the 384-well microplates often used in HTS. Of course, full-scale HTS using FAMA will require detailed consideration of the FAMA's precision, quality ( $\mathrm{Z}^{\prime}$ factor; Reference 33), and issues of compound fluorescence (18). However, our ability to assay different steroid receptors and to screen for compounds that work preferentially on a single receptor should minimize problems due to intrinsic fluorescence or the inhibition of receptor binding by interaction of compounds with the DNA. Compounds with intrinsic fluorescence or that fluoresce when bound to DNA, will fluoresce in the presence of the probe alone, and this can usually be corrected. Small molecules that inhibit receptor binding through an interaction with the DNA and not the receptor protein are unlikely to show sequence specificity and will therefore usually inhibit both ER and PR binding to their DNAs; consequently, these compounds would be unlikely to emerge as falsepositive candidates for receptor-selective agents. In the screen of several zinc chelators for inhibiting binding of ERs and PR to their response elements, we found that the PR was considerably more sensitive to inhibition than the ERs. These small-scale experiments illustrate the potential of FAMA for HTS applications focused on identification of small molecules that will selectively antagonize (or stimulate) the interaction of a specific steroid hormone receptor with its DNA response element.

\section{ACKNOWLEDGMENTS}

We are grateful to Drs. C. Royer, A. Tamrazi, and J. Katzenellenbogen for encouragement and helpful advice at the start of this work and to Dr. B. Freeman for use of his fluorometer. This research was supported by National Institutes of Health (NIH) grant nos. HD-16720 and DK-50080 (to D.J.S.) and $D K-37061$ and $D K / H D-62362$ (to S.K.N.).

\section{COMPETING INTERESTS STATEMENT}

The authors declare no competing interests.

\section{REFERENCES}

1.Jordan, V.C. 2001. The past, present, and future of selective estrogen receptor modulation. Ann. N.Y. Acad. Sci. 949:72-79.

2.Lieberman, R. 2002. Chemoprevention of prostate cancer: current status and future directions. Cancer Metastasis Rev. 21:297-309.

3.Wang, L.H., X.Y. Yang, X. Zhang, K. Mihalic, Y.X. Fan, W. Xiao, O.M. Howard, E Appella, et al. 2004. Suppression of breast cancer by chemical modulation of vulnerable zinc fingers in estrogen receptor. Nat. Med. 10:40-47.

4.Hall, J.M., D.P. McDonnell, and K.S. Ko- 
rach. 2002. Allosteric regulation of estrogen receptor structure, function, and coactivator recruitment by different estrogen response elements. Mol. Endocrinol. 16:469-486.

5.Klinge, C.M., S.C. Jernigan, S.L. Smith, V.V. Tyulmenkov, and P.C. Kulakosky. 2001. Estrogen response element sequence impacts the conformation and transcriptional activity of estrogen receptor alpha. Mol. Cell. Endocrinol. 174:151-166.

6.Loven, M.A., V.S. Likhite, I. Choi, and A.M. Nardulli. 2001. Estrogen response elements alter coactivator recruitment through allosteric modulation of estrogen receptor beta conformation. J. Biol. Chem. 276:45282-45288.

7.Ramsey, T.L., K.E. Risinger, S.C. Jernigan, K.A. Mattingly, and C.M. Klinge. 2004. Estrogen receptor beta isoforms exhibit differences in ligand-activated transcriptional activity in an estrogen response element sequence-dependent manner. Endocrinology 145:149-160.

8.Schultz, J.R., M.A. Loven, V.M. Melvin, D.P. Edwards, and A.M. Nardulli. 2002. Differential modulation of DNA conformation by estrogen receptors alpha and beta. J. Biol. Chem. 277:8702-8707.

9.Yi, P., M.D. Driscoll, J. Huang, S. Bhagat, R. Hilf, R.A. Bambara, and M. Muyan. 2002. The effects of estrogen-responsive element- and ligand-induced structural changes on the recruitment of cofactors and transcriptional responses by ER alpha and ER beta. Mol. Endocrinol. 16:674-693.

10.Dana, S.L., P.A. Hoener, D.A. Wheeler, C.B. Lawrence, and D.P. McDonnell. 1994. Novel estrogen response elements identified by genetic selection in yeast are differentially responsive to estrogens and antiestrogens in mammalian cells. Mol. Endocrinol. 8:11931207.

11.Hyder, S.M., C. Chiappetta, and G.M. Stancel. 1999. Interaction of human estrogen receptors alpha and beta with the same naturally occurring estrogen response elements. Biochem. Pharmacol. 57:597-601.

12.Klinge, C.M. 2001. Estrogen receptor interaction with estrogen response elements. Nucleic Acids Res. 29:2905-2919.

13.Loven, M.A., J.R. Wood, and A.M. Nardulli. 2001. Interaction of estrogen receptors alpha and beta with estrogen response elements. Mol. Cell. Endocrinol. 181:151-163.

14.Nardulli, A.M., L.E. Romine, C. Carpo, G.L. Greene, and B Rainish. 1996. Estrogen receptor affinity and location of consensus and imperfect estrogen response elements influence transcription activation of simplified promoters. Mol. Endocrinol. 10:694-704.

15.Boyer, M., N. Poujol, E. Margeat, and C.A. Royer. 2000. Quantitative characterization of the interaction between purified human estrogen receptor alpha and DNA using fluorescence anisotropy. Nucleic Acids Res. 28:2494-2502.

16.Ozers, M.S., J.J. Hill, K. Ervin, J.R. Wood, A.M. Nardulli, C.A. Royer, and J. Gorski. 1997. Equilibrium binding of estrogen receptor with DNA using fluorescence anisotropy. J. Biol. Chem. 272:30405-30411.

17.Burke, T.J., K.R. Loniello, J.A. Beebe, and K.M. Ervin. 2003. Development and appli- cation of fluorescence polarization assays in drug discovery. Comb. Chem. High Throughput Screen. 6:183-194.

18.Owicki, J.C. 2000. Fluorescence polarization and anisotropy in high throughput screening: perspectives and primer. J. Biomol. Screen. 5:297-306

19.Lin, S., C.L. Bock, D.B. Gardner, J.C. Webster, M.F. Favata, J.M. Trzaskos, and K.R. Oldenburg. 2002. A high-throughput fluorescent polarization assay for nuclear receptor binding utilizing crude receptor extract. Anal. Biochem. 300:15-21.

20.Sportsman, J.R. and L.J. Leytes. 2000. Miniaturization of homogeneous assays using fluorescence polarization. Drug Discov. Today: HTS Supplement. 1:27-32.

21.Sabbah, M., G. Redeuilh, C. Secco, and E.E. Baulieu. 1987. The binding activity of estrogen receptor to DNA and heat shock protein $(\mathrm{Mr} 90,000)$ is dependent on receptorbound metal. J. Biol. Chem. 262:8631-8635.

22.Krieg, A.J., S.A. Krieg, B.S. Ahn, and D.J. Shapiro. 2004. Interplay between estrogen response element sequence and ligands controls in vivo binding of estrogen receptor to regulated genes. J. Biol. Chem. 279:5025-5034.

23.Zhang, C.C., S. Krieg, and D.J. Shapiro. 1999. HMG-1 stimulates estrogen response element binding by estrogen receptor from stably transfected HeLa cells. Mol. Endocrinol. 13:632-643.

24.Melvin, V.S. and D.P. Edwards. 2001. Expression and purification of recombinant human progesterone receptor in baculovirus and bacterial systems, p. 39-54. In B.A. Lieberman (Ed.), Steroid Receptor Methods: Protocols and Assays. Humana Press, Totawa, NJ.

25.Krieg, S.A., A.J. Krieg, and D.J. Shapiro. 2001. A unique downstream estrogen responsive unit mediates estrogen induction of proteinase inhibitor-9, a cellular inhibitor of IL-1beta-converting enzyme (caspase 1). Mol. Endocrinol. 15:1971-1982.

26.Kanamori, H., S. Krieg, C. Mao, V.A. Di Pippo, S. Wang, D.A. Zajchowski, and D.J. Shapiro. 2000. Proteinase inhibitor 9, an inhibitor of granzyme B-mediated apoptosis, is a primary estrogen-inducible gene in human liver cells. J. Biol. Chem. 275:5867-5873.

27.Kuiper, G.G. and J.A. Gustafsson. 1997. The novel estrogen receptor-beta subtype: potential role in the cell- and promoter-specific actions of estrogens and anti-estrogens. FEBS Lett. 410:87-90.

28.Margeat, E., A. Bourdoncle, R. Margueron, N. Poujol, V. Cavailles, and C. Royer. 2003. Ligands differentially modulate the protein interactions of the human estrogen receptors alpha and beta. J. Mol. Biol. 326:77-92.

29.Edwards, D.P. 2000. The role of coactivators and corepressors in the biology and mechanism of action of steroid hormone receptors. Mammary Gland Biol. Neoplasia 5:307-324.

30.Bramlett, K.S., Y. Wu, and T.P. Burris. 2001. Ligands specify coactivator nuclear receptor (NR) box affinity for estrogen receptor subtypes. Mol. Endocrinol. 15:909-922.

31.Rodriguez, A.L., A. Tamrazi, M.L. Collins, and J.A. Katzenellenbogen. 2004. Design, synthesis, and in vitro biological evaluation of small molecule inhibitors of estrogen recep- tor alpha coactivator binding. J. Med. Chem. 47:600-611.

32.Chen, C.D., D.S. Welsbie, C. Tran, S.H. Baek, R. Chen, R. Vessella, M.G. Rosenfeld, and C.L. Sawyers. 2004. Molecular determinants of resistance to antiandrogen therapy. Nat. Med. 10:33-39.

33.Zhang, J.H., T.D. Chung, and K.R. Oldenburg. 1999. A simple statistical parameter for use in evaluation and validation of high throughput screening assays. J. Biomol. Screen. 4:67-73.

Received 13 April 2004; accepted 26 July 2004.

Address correspondence to:

David J. Shapiro

Department of Biochemistry

University of Illinois

600 S. Mathews Avenue

Urbana, IL 61801-3602, USA

e-mail:djshapir@uiuc.edu 